PESHAWAR JOURNAL OF PSYCHOLOGY AND BEHAVIORAL SCIENCES, 2018, VOL. 4, NO. 1, 139-152

\title{
Neuropsychological Impairment among Juvenile Delinquents
}

\author{
Hina Iqbal', Madiha Asghar' ${ }^{2}$, Gulshan Tara ${ }^{3}$ \\ Islamia College Peshawar \\ and
}

\author{
Musarrat Zahra ${ }^{4}$ \\ Gajju Khan Medical College, Swabi
}

The aim of the present study was to investigate the role of neuropsychological impairment among delinquents and nondelinquents. The total sample comprised of two hundred participants consisting of one hundred juvenile and non-juvenile with age range of 10-17 years $(\mathrm{M}=15.76, \mathrm{SD}=1.93)$. Data was collected from the incarcerated subjects from three main jails of Khyber Pakhtunkhwa they include, Central Prisons of Kohat, Peshawar Swabi and Haripur with the help of Psychologists serving in the prison. It was hypothesized that delinquents will score higher on neuropsychological impairment scale as compared to non-delinquents. Neuropsychological impairment will be significantly correlated with the scores of delinquency. The results revealed significant impairment in the neurological functioning of the delinquents as compared to non-delinquents. In the present study six neuropsychological deficits were measured, they included neuropsychological emotional, learning, sensory motor, concentration, and neuropsychological depression in association with delinquency. Hence the results produced three key findings, first the sub-scales of

\footnotetext{
${ }^{1}$ Lecturer, Department of Psychology, Islamia College Peshawar

2 Assistant Professor, Department of Psychology, Islamia College Peshawar

${ }^{3}$ Assistant Professor, Gajju Khan Medical College, Swabi

${ }^{4}$ Lecturer, Department of Psychology, Islamia College Peshawar
}

ISSN 2415-6779 EISSN 2518-4474

https://doi.org/10.32879/picp.2018.4.1.139

www.pjpbsicp.com 
neuropsychological impairment were significantly positively associated with delinquency. Second, sub-scales of neuropsychological impairment predicted variation in the magnitude of association with delinquency. Third, of all the six sub-scales neuropsychological emotional problems, neuropsychological motor problems and neuropsychological depression were slightly strongly associated with delinquency as compared to learning, sensory motor and concentration problem.

Keywords: delinquent, neuropsychological impairment, neuropsychological emotional problems, learning problems, sensory motor problems, concentration problems and neuropsychological depression

Delinquency is on rise in both developed and developing countries around the globe (Carter, S. P., \& Stewin, L. L. 1999; Haper, F. D, \& Ibrahim, F. A. 1999). Juvenile delinquency is a great challenge for parents, policy makers, law-enforcement agencies and mental health practitioners to overcome this problem. The term delinquency is used to describe those between the age of 10-18 years, deviating from the norms of the society, resulting in extreme problematic behavior or committing a crime (Schwartz \& Johnson, 1985). Delinquency has always been part of the human existence, and criminal behavior has always been a focus of attention for researchers and policy makers. Among the different causal factors neuropsychological impairments are considered as an important causal factor of delinquent behavior (Moffitt, 1993b).

Neuropsychological studies carried out with juvenile delinquents have demonstrated association between neuropsychological variables and delinquency (Gorenstein, 1990; Kandel \& Freed, 1989; Miller, 1988; Moffitt, 1990b; 1993b; Yeudall, Fedora, \& Fromm, 1987). Similar findings were revealed from studies that frequently used EEG, neurological examinations, or neuropsychological tests (Krynicki, 1978; McManus, Brickman, Alessi, \& Grapentine, 1985; Yeudall, FrommAuch, \& Davies, 1982). It may be concluded from these studies that neurobehavioral tests identify a greater frequency of CNS abnormalities in juvenile delinquent.

Individuals with fierce behavior shows impairment on neuropsychological tests such as executive functioning of the offenders were found to be associated with focal frontal lobe that includes 
planning, self-monitoring, organization, inhibition, mental representation of tasks, cognitive flexibility and representation of tasks and goals (Ozonoff et al., 2004).

Rozalski, Deignan and Engel (2008) examined the occurrence of learning and mischief disabilities among school aged children and those who were imprisoned. Neuropsychological impairment is consider to be important element for causing delinquency (Wolff, Waber, Bauermeister, Cohen, \& Ferber, 1982). Moffitt, Caspi, Rutter and Silva (2001) further suggested that a child's risk of developing antisocial behavior emerged from 'acquired neuropsychological variation, initially manifested as subtle cognitive deficits, difficult temperament or hyperactivity'.

Juvenile delinquency have been found to be linked to emotional problems (Callahan \& Froehle, 2000; Dembo \& Schmeidler, 2003; Loeber \& Farrington, 1998; Loeber, Farrington, Stouthamer-Loeber, \& Van Kammen, 1998; McCord, Widom, \& Crowell, 2003; StouthamerLoeber \& Loeber, 2002), learning problems (Mallett, 2003), sensory motor problems (Fanchiang S. P, Snyder C, Zobel-Lachiusa J, Loeffler C. B, Thompson M. E., 1990), concentration problems (Loeber,1987) and depression (Akse et al. 2007 ;Brianna Remster, 2014; De Coster and Heimer 2001)

Juvenile delinquents have low level of executive functioning (Giancola, 2000; Ross \& Hoaken, 2010) and low level of IQ which decreases academic achievement (Leone, Meisel, \&Drakeford, 2000). Kelly al. (2002) examined that juvenile delinquents has disturbed working memory and inability to sustained attention and inhibition and disturbed verbal fluency. Gorenstein (1982) conducted an experiment and found that delinquents scores lower on three test (Wisconsin card sort test, Sequential matching memory test, Necker cube Reversals) which measures frontal lobe functioning than non-delinquents. Nachson's (1983) found that due to hemispheric dysfunctions delinquent has higher scores on performance IQ than verbal IQ. Raine and Venables (1992) assumed that delinquents are more prone towards schizoid personality disorder and due to frontal lobe dysfunction as it causes schizophrenia. Moffitt and Henry, (1991) intemperate juvenile performed worse on verbal and memory function scale.

Juvenile delinquency is a global behavioral issue, the researchers, policy makers, educationists; people belonging to different social institutions, law enforcement agencies and judiciary, etc. of the

PESHAWAR JOURNAL OF PSYCHOLOGY AND BEHAVIORAL SCIENCES, 2018,VOL. 4, NO. 1, 139-152 
world particularly Pakistan are seriously concerned about addressing this problem. Neuropsychology of delinquency is the most neglected area and it requires special attention for detailed investigation. The main aim of the present study is to find the association between delinquency and neuropsychological impairment among juvenile delinquents and to investigate the difference between the scores of neuropsychological impairment between delinquents and non-delinquents. Youth under 18 years of age are involved in various kinds of criminal activities such as theft, drugs, and as serious crimes as suicide bombers etc. Neuropsychological disturbance will be studied and compared among detained juvenile delinquents and non-delinquents who will help in drawing conclusion about the association between neuropsychological impairment and delinquency. The present research is an effort to highlight some of the facts and figures associated with delinquency and its comparison with non-delinquents.

\section{Objective:}

1. To study the role of neuropsychological impairment in detained delinquents and non-delinquents

2. To investigate the difference between delinquents and nondelinquents on sub-scales of neuropsychological impairment

\section{Hypotheses}

1. There will be positive relationship between neuropsychological impairment and delinquency among delinquents and non-delinquents.

2. Juvenile delinquents will reveal more neuropsychological problems as compared to non-delinquents.

\section{Method}

\section{Sample}

The sample consisted of the total two hundred $(\mathrm{N}=200)$ delinquents and non-delinquents with age range of $11-17$ years $(\mathrm{M}=15.7 \mathrm{SD}=1.94)$. It consisted of one hundred $(n=100)$ detained juvenile delinquents and one hundred( $\mathrm{n}=100)$ non delinquents from district Banu, Peshawar and Haripur of Khyber Pakhtunkhwa, Pakistan. Detained delinquents were comprised of all the delinquents in Central Prisons of Kohat, Peshawar

PESHAWAR JOURNAL OF PSYCHOLOGY AND BEHAVIORAL SCIENCES, 2018, VOL. 4, NO.1, 139-152 
Swabi and Haripur of Khyber Pakhtunkhwa. Non delinquents were selected from the schools of same districts of the Khyber Pakhtunkhwa, Pakistan. Random sampling technique was used for selection of sample with in each Central Prison selected for the data collection. Criteria for selection of the delinquents was selection of children with age range of 10-17 years incarcerated in the selected central Prisons of Khyber Pakhtunkhwa and score higher than 27 on delinquency scale. Mean score on delinquency scale of the delinquents was $(\mathrm{M}=34.95 \mathrm{SD}=14.54)$ whereas the score of non-delinquents on delinquency scale was $(\mathrm{M}=$ $3.94 \mathrm{SD}=5.03)$.

\section{Instruments}

\section{Self-Reported Delinquency Scale}

This scale was developed and by Irum Naqvi (2007). The basic purpose is to measure the juvenile tendencies, it comprises of twentyseven items. It is a self-reported measure constructed in Urdu so that Pakistani citizens can understand and answer the questions. The lowest score on the scale is 27 whereas highest score is 135 . High scores on the scale show high delinquent tendencies while low score indicates less delinquent tendencies among young adulthood. The reliability of the test is .76 .

\section{Neuropsychological Impairment Scale (NPIS)}

The Neuropsychological Impairment scale developed by ( $\mathrm{S}$ Riffat Naheed, 2000)in Urdu language for stroke patients. It is a highly reliable scale with alpha reliability of .95 . The NPIS comprised of total 46 items, the sub-scales and the number of the items included, emotional problem dimensions consist of 10 items. The learning problem consists of 6 items. The sensory and motor problems has 6 items. The concentration problems has 8 items and the mental and the physical incoordination consists of 4 items. The rest of the items have been derived from Siddiqui-shah (1977) Depression scale, SSD (12 items).

\section{Procedure}

The study formally initiated with the formal permission from jail department and schools of Khyber Pakhtunkhwa. Data was individually collected from the jails with the help of psychologist working in jail due to current law and order situation in Khyber Pakhtunkhwa. 
Questionnaires were filled in group in school children in their schools. Before formal data collection a consent letter was signed by every subject and was briefed about the study. Rapport was established and all the non-delinquents were given questionnaire in the same sequence and were requested for their honest replies. However delinquents were individually interviewed in a same sequence by a trained psychologist working in the jail.

Table 1

Correlation of the Study Variables Between the Scores of Delinquency and Sub-scales of Neuropsychological Impairment Scale $(N=200)$

\begin{tabular}{|c|c|c|c|c|c|c|c|c|c|c|}
\hline & Variables & 1 & 2 & 3 & 4 & 5 & 6 & 7 & Mean & SD \\
\hline 1 & Delin & - & $.58 * * *$ & $.37 * * *$ & $.42 * * *$ & $.46 * * *$ & $.47 * * *$ & $.53 * * *$ & 3.94 & 5.03 \\
\hline 2 & NPEP & $.39 * * *$ & - & $.42 * * *$ & $.51 * * *$ & $.58 * * *$ & $.56 * * *$ & $.69^{* * *}$ & 14.16 & 4.29 \\
\hline 3 & NPLP & $.21 *$ & $.40 * * *$ & - & $.52 * * *$ & $.68 * * *$ & $.62 * * *$ & $.41^{* * *}$ & 7.35 & 2.10 \\
\hline 4 & NPSM & $.35 * * *$ & $.47 * * *$ & $.41 * * *$ & - & $.48 * * *$ & $.51 * * *$ & $.61 * * *$ & 6.99 & 1.90 \\
\hline 5 & NPCon & $.36 * * *$ & $.48 * * *$ & $.45^{* * *}$ & $.55 * * *$ & - & $.65 * * *$ & $.48 * * *$ & 12.23 & 3.56 \\
\hline 6 & NPMP & $.41 * * *$ & $.52^{* * * *}$ & $.44 * * *$ & $.47 * * *$ & $.51 * * *$ & & $.48^{* * *}$ & 5.65 & 1.56 \\
\hline \multirow[t]{3}{*}{7} & NPDEP & $.39 * * *$ & $.62^{* * * *}$ & $.31^{* *}$ & $.53 * * *$ & $.47 * * *$ & $.55 * * *$ & - & 15.37 & 3.93 \\
\hline & Mean & 34.95 & 23.05 & 10.69 & 11.53 & 17.62 & 8.69 & 26.62 & - & - \\
\hline & SD & 14.54 & 4.91 & 2.25 & 2.54 & 3.59 & 2.06 & 5.71 & - & - \\
\hline \multicolumn{11}{|c|}{$\begin{array}{l}\text { Note: }{ }^{*} p<.05, *_{p}^{*}<.01, *^{*} p<.001 ; \text { Delin: Delinquency, NPEP: Neuropsychological } \\
\text { emotional problem, NPLP: Neuropsychological Learning problem, NPSM: } \\
\text { Neuropsychological sensory motor problem, NPCon: Neuropsychological concentration, } \\
\text { NPMP: Neuropsychological motor problem, NPDEP; Neuropsychological Depression. } \\
\text { Intercorrelation for delinquents }(n=100) \text { are presented below the diagonal line and } \\
\text { intercorrelation for non-delinquents }(n=100) \text { are presented above the diagonal line. } \\
\text { Mean and standard deviation are for delinquents are presented in horizontal rows. Mean } \\
\text { and standard deviation for non-delinquents are presented in vertical columns. }\end{array}$} \\
\hline
\end{tabular}

PESHAWAR JOURNAL OF PSYCHOLOGY AND BEHAVIORAL SCIENCES, 2018, VOL. 4, NO.1, 139-152 
Table 2

Mean Difference, Standard Deviation, t-Value of Delinquents and Non Delinquents on Sub Scale of Neuropsychological Impairment Scale $(N=200)$

\begin{tabular}{|c|c|c|c|c|c|c|c|c|}
\hline \multirow[b]{2}{*}{ Variable } & \multicolumn{2}{|c|}{$\begin{array}{l}\text { Delinquents } \\
\quad(n=100)\end{array}$} & \multicolumn{2}{|c|}{$\begin{array}{c}\text { Non- } \\
\text { Delinquents } \\
(n=100)\end{array}$} & \multirow[b]{2}{*}{ t (198) } & \multicolumn{2}{|c|}{$95 \% \mathrm{CI}$} & \multirow{2}{*}{$\begin{array}{c}\text { Cohen's } \\
\text { d }\end{array}$} \\
\hline & Mean & $S D$ & Mean & $S D$ & & LL & UL & \\
\hline NPEP & 23.05 & 4.91 & 14.16 & 4.28 & $-13.64 * * *$ & -10.17 & -7.60 & 1.93 \\
\hline NPLP & 10.69 & 2.25 & 7.35 & 2.09 & $-10.86^{* * *}$ & -3.94 & -2.73 & 1.53 \\
\hline NPSM & 11.53 & 2.54 & 6.99 & 1.89 & $-14.30 * * *$ & -5.16 & -3.91 & 2.02 \\
\hline NPCon & 17.62 & 3.60 & 12.23 & 3.56 & $-10.64 * * *$ & -6.38 & -4.39 & 1.50 \\
\hline NPMP & 8.69 & 2.06 & 5.65 & 1.56 & $-11.75 * * *$ & -3.55 & -2.53 & 1.66 \\
\hline NPDEP & 26.62 & 5.71 & 15.37 & 3.93 & $-16.21 * * *$ & -12.61 & -9.88 & 2.28 \\
\hline
\end{tabular}

Table 2 shows significant difference between delinquents and non-delinquents. On sub scale of sensory motor problem Delinquents $(\mathrm{M}=11.53, \mathrm{SD}=2.54)$ scored higher than non -delinquents $(\mathrm{M}=6.99, \mathrm{SD}=$ 2.09). $\mathrm{t}(198)=-14.30$ with mean difference $4.54, \mathrm{p}<.001 ; \mathrm{d}=2.02$, CI $95 \%[-5.16,-3.91]$. The effect size for this analysis was found to exceed Cohen's d (1988) convention for large effect $(\mathrm{d}=.80)$.

Table 2 shows the significant difference between delinquents and non -delinquent. On DS Delinquents $(\mathrm{M}=26.62, \mathrm{SD}=5.71)$ scored higher than non -delinquents $(\mathrm{M}=15.37, \mathrm{SD}=3.99),(198)=-16.12$, with mean difference $11.25, \mathrm{p}<.001 ; \mathrm{d}=2.28, \mathrm{CI} 95 \%$ [-12.62, -9.87]. The effect size of this analysis was found to exceed Cohen's d (1988) convention for large effect $(\mathrm{d}=.80)$.

The table shows the result on the sub-scale of depression scale. The result shows significant difference between scores of delinquents and non- delinquents on depression. Delinquents $(\mathrm{M}=23.05, \mathrm{SD}=4.91)$ scored higher than non- delinquents $(\mathrm{M}=14.16, \mathrm{SD}=4.28), \mathrm{t}(198)=-$ 13.63, with mean difference of $8.89, \mathrm{p}<.001$; CI $95 \%$ [-10.17, -7.60]. The effect size $d=1.9$ for this analysis was found to exceed Cohen's $d$ (1988) convention for large effect $(\mathrm{d}=.80)$. 
Table 3

Logistic Regression Analysis of Neuropsychological Problem among Delinquents and Non delinquents $(N=200)$

\begin{tabular}{llccc}
\hline \multirow{2}{*}{ Variables } & $\mathrm{b}(\mathrm{SE})$ & \multicolumn{3}{c}{$95 \%$ CI for Odds Ratio } \\
\cline { 3 - 5 } & & Lower & $\begin{array}{l}\text { Odds } \\
\text { Ratio }\end{array}$ & Upper \\
\hline Constant & $-11.36(1.66)^{* * *}$ & & & \\
NPEP & $.09(.081)$ & .93 & 1.09 & 1.27 \\
NPLP & $.20(.148)$ & 91 & 1.21 & 1.62 \\
NPSM & $.37(.154)^{* *}$ & 1.07 & 1.44 & 1.95 \\
NP con & $-.05(.104)$ & .776 & .95 & 1.16 \\
NPMP & $.09(.195)$ & .744 & 1.09 & 1.59 \\
NPDEP & $.24(.07)^{* * *}$ & 1.10 & 1.26 & 1.45 \\
\hline Note: $R 2=.58($ Cox \&Snell), R2 $=.78$ (Nagelkerke). Model Chi-Sq. $(d f=6), 174.57, p$ \\
value $=.001$. \\
$*=p<.05, * *=p<.01 \& * * *=p<.001$.
\end{tabular}

A logistic regression model was used to predict neuropsychological emotional problem, neuropsychological learning problem, neuropsychological sensory motor problem (NPSM), neuropsychological concentration problem (NP Con), neuropsychological motor problem(NPMP) and neuropsychological depression (NPDEP) as for finding difference between delinquents and non-delinquents is statistically significantly related with neuropsychological sensory motor problem (NPSM) and neuropsychological depression (NPDEP) $(174.57, \mathrm{p}<.001, \mathrm{df}=6)$ and less significant with neuropsychological learning problem, neuropsychological concentration problem (NPCon) and neuropsychological motor problem(NPMP). The waldan criterion demonstrate neuropsychological sensory motor problem and neuropsychological depression made a significant contribution to prediction of delinquency $(\mathrm{p}<.001)$. Neuropsychological concentration, neuropsychological motor problem was not statistically significant.

\section{Discussion}

Aim of this study was to investigate the neuropsychological impairment among juvenile delinquents and non-delinquents. Results on the basis of statistical analysis have been discussed thoroughly for each hypothesis.

PESHAWAR JOURNAL OF PSYCHOLOGY AND BEHAVIORAL SCIENCES, 2018, VOL. 4, NO.1, 139-152 
The juvenile delinquents reveal more neuropsychological problem than non-delinquents. Regarding this it has been found that frontal lobe is responsible for inhibition and when it gets damaged the individual lose their inhibition control. Subjects with damage to the prefrontal cortex were found to be more susceptible to antisocial traits such as delinquency (Davidson et al., 2000; Raine et al., 1998, 2000). Executive functioning is higher order functioning of the human brain that deals with problem solving ability and cognitive abilities the present study reveals association between learning problem and delinquency that depicts that juvenile delinquents are low in learning skills as it has been consistent with previous research that Morgan and Lilienfeld (2000) found a significant relationship between executive function deficits and delinquency.

One of noteworthy point of the current study is that juvenile delinquents face problem in switching their attention, their inability is regarding their cognitive fixation and when they cannot switch their attention properly they may face problem in memorizing thing and making plan for future, the findings are consistent with the past studies which proved thatit has been found through previous research that working memory and forthcoming memory has strong relationship with each other(Smith, Persyn, \&Butler, 2011).Those having poor working memory and forthcoming memory they have worst level of switching attention(Redick, Calvo, Gay, \& Engle, 2011). As reported that juvenile delinquent has poor level of shifting of attention this problem may be cause due to impair functioning of Frontal lobe (Stone \& Thompson, 2001): and impairment in basal ganglia. Working memory is the part of executive functioning in working memory usually an individual retrieve, retain, and recall the material and juvenile delinquents has weak working memory for example juvenile face problem in memorizing the material and then recalling the material so through this phenomenon juvenile usually consider under IQ. These results support the findings of this study that revealed that the delinquents scored higher on neuropsychological problems related to learning as compared to nondelinquents.

Kelly et al. (2002) conducted a prospective study in which they found that juvenile delinquents have impaired working recollection, like they have problem in constant concentration and on the other side they have weaken tie with inhibition and fluent verbal ability. While Leone, Meisel and Drakeford, (2002) concluded remarks about juvenile 
delinquent they have low IQ so they need correctional education. As reported earlier that due to low IQ it hampers their performance, for a performance an individual needs verbal ability and the ability to perform task practically it is consistent with the previous study that Veneziano et al. (2004) found that juvenile delinquents scores lower on different neuropsychological tests than non-delinquents.

Neuropsychological impairment is high among delinquents as compared to non-delinquents. The basic reason is that emotional and psychological trauma is very common in delinquents as compared to non-delinquents. Low emotional self-acceptance, emotional regulation may have effect on child's neuropsychological condition. On the other hand the possibility of the parental neglect or abusive behavior of parent leads a child to delinquency. Neuropsychological sensory motor problem is relatively high in delinquents because of high level of exposure of substance abuse on the other hand non delinquents are not exposed to life threatening substance abuse. The neuropsychological depression is very common among delinquents because of their bad activities and due to blockage in their life goal. They only achieve goal by their negative behavior while non- delinquents can achieve goal by different strategies.

\section{Conclusion}

The study found that juvenile delinquents reported high score on neuropsychological impairment scale as compared to non-delinquents. That indicates vulnerability of delinquents to the neuropsychological problems and its association with delinquency. Neuropsychological emotional problems, neuropsychological sensory motor problem, and neuropsychological depression were found to be strongly associated with delinquency.

\section{Limitations}

- Small sample size and variety of method used in the data collection such as interview method with delinquents and administering the tests in group among non-delinquent group of school children

- Due to strict law and order situation the research was not allowed to collect data from the delinquents and the data was collected through the psychologists of prison.

PESHAWAR JOURNAL OF PSYCHOLOGY AND BEHAVIORAL SCIENCES, 2018, VOL. 4, NO.1, 139-152 


\section{Recommendation}

Future neurological studies may include larger sample size with focus on severity of the crime, as offenders who are non-violent and violent offenders may be separately studied.

Studies related to cognitive functioning, executive functioning may help in better understanding of the causes of the persistent antisocial personality traits

\section{Acknowledgement}

We are grateful to the Prison authorities of Khyber Pakhtunkhwa, Pakistan who supported us in data collection. Thanks are extended to all the principals of the schools who allowed and cooperated in the data collection. Thanks to all the adolescents who participated in the study and make this study possible with their participation in the study.

\section{References}

Akse, Joyce, Bill Hale, Rutger Engels, Quinten Raaijmakers, and Wim Meeus. (2007). "Co-Occurrence of Depression and Delinquency in Personality Types.”' European Journal of Personality 21:235256.

Brianna Remster (2014) Self-Control and the Depression-Delinquency Link. Deviant Behavior, 35: 66-84, 2014. DOI: $10.1080 / 01639625.2013 .822226$

Callahan, J., \& Froehle, M. (2000), Arrested Development: Substance Abuse and Mental Illness Among Juveniles Detained in New York City. New York, NY: Vera Institute of Justice.

Carter, S. P., \&Stewin, L. L. (1999). School Violence in the Canadian Content: An Overview and Model for Intervention. International Journal for the Advancement of Counseling, 21 (4): 267-277.

De Coster, Stacy and Karen Heimer. 2001. "The Relationship between Law Violation and Depression: An Interactionist Analysis." Criminology 39:799-836.

Dembo, R., \& Schmeidler, J. (2003). A classification of high-risk youths. Crime \& Delinquency 49 (2), 201-230.

Fanchiang S. P, Snyder C, Zobel-Lachiusa J, Loeffler C. B, Thompson M. E., (1990). Sensory integrative processing in delinquent-

PESHAWAR JOURNAL OF PSYCHOLOGY AND BEHAVIORAL SCIENCES, 2018,VOL. 4, NO. 1, 139-152 
prone and non-delinquent-prone adolescents. Am J Occup Ther. 1990 Jul;44(7):630-9.

Giancola, P. R. (2000). Neuropsychological functioning and antisocial behavior: Implications for etiology and prevention. In E. H. Fishbein (Ed.), The science, treatment, and prevention of antisocial behaviors: Application to the criminal justice system (Vol. 1, pp. 11-1 to 11-16). Kingston, NJ: Civil Research Institute.

Gorenstein, E. (1982). Frontal lobe function in psychopaths. Journal of Abnormal Psychology. 91 (5), 368-379.

Gorenstein, E. E. (1990). Neuropsychology of juvenile delinquency. Forensic Reports, 3, 15-48.

Haper, F. D, \& Ibrahim, F. A. (1999). Violence and Schools in the USA: Implication for Counseling. International Journal for the Advancement of Counseling, 21 (4): 349-366.

Joyal, C. C., Black, D. N., \& Dassylva, B. (2007). The neuropsychology and neurology of sexual deviance: A review and pilot study. Sexual Abuse, 19, 155-173. doi:10.1177/ 107906320701900206.

Kandel, E., \& Freed, D. (1989). Frontal-lobe dysfunction and antisocial behavior: A review. Journal of Clinical Psychology. 45, 404413.

Kelly, T., Richardson, G., Hunter, R., \& Knapp, M. (2002). Attention and executive function deficits in adolescent sex offenders. Child Neuropsychology, 8, 138-143.

Leone, P. E., Meisel, S. M., \& Drakeford, W. (2002). Special education programs for youth with disabilities in juvenile corrections. Journal of Correctional Education, 53, 46-50.

Liau, A. K., Liau, A. W. L., Teoh, G. B. S., \& Liau, M. T. L. (2003). The Case for Emotional Literacy: The influence of emotional intelligence on problem behaviors in Malaysian secondary school students. Journal of Moral Education, 32, 5166.doi:10.1080/0305724022000073338

Loeber, R., \& Farrington, D.P. (1998). Never too early, never too late: risk factors and successful interventions for serious and violent juvenile offenders. Studies on Crime and Crime Prevention 7 (1), 7-30.

Loeber, R., \& Farrington, D.P. (1998). Never too early, never too late: risk factors and successful interventions for serious and violent

PESHAWAR JOURNAL OF PSYCHOLOGY AND BEHAVIORAL SCIENCES, 2018, VOL. 4, NO.1, 139-152 
juvenile offenders. Studies on Crime and Crime Prevention 7 (1), 7-30.

Mallett, C. (2003). Socio-historical analysis of juvenile offenders on death row. Criminal Law Bulletin, 39(4), 455-468.

McCord, J. Widom, C.S., \& Crowell, N.A. (Eds.). (2003). Juvenile Crime, Juvenile Justice. Washington, D.C.: National Academy Press.

Miller, L. (1988). Neuropsychological perspectives on delinquency. Behavioral Sciences and the Law, 6, 409-428.

Moffitt, T. E. (1990b). The neuropsychology of juvenile delinquency: A critical review of research and theory. In N. Morris \& M. Tonry (Eds.), Crime and justice: An annual review of research (Vol. 12, pp. 99-169). Chicago, IL: University of Chicago Press.

Moffitt, T. E. (1993a). Adolescence-limited and life-course-persistent antisocial behavior: A developmental taxonomy. Psychological Re-view, 100,647-701.

Moffitt, T. E. (1993b). The neuropsychology of conduct disorder. Development and Psychopathology, 5, 135-151.

Moffitt, T.E. and Henry, B. (1991). Neuropsychological studies of juvenile delinquency and violence: A review. In J. Milner (Ed.), The neuropsychology of aggression, (pp. 67-91). Norwell, MA: Kluwer Academic.

Moffitt, T.E., \& Silva, P.A. (1998). Self-reported delinquency, neuropsychological deficit and history of attention deficit disorder. Journal of Abnormal Child Psychology, 16, 553-569.

Nachson, I. (1983). Hemisphere dysfunction in psychopathy and behavior disorders. In M.S. Myslobodsky (Ed.), Hemisvndromes: Psychobiology. Neurology, and Psychiatry. New York: Academic Press.

Naheed S. R. (2000). Neuropsychology and role of family support in improvement of stroke patients (Unpublished doctoral dissertation). National Institute of Psychology, Quaid e AzamUniversity, Islamabad, Pakistan. Retrieved from: http://prr.hec.gov.pk/jspui/bitstream/123456789/5596/1/2348.pdf

Ozonoff, S., Cook, I., Coon, H., Dawson, G., Joseph, R.M., Klin, A., McMahon, W.M., Minshew, N., Munson, J.A., Pennington, B.F., Rogers, S.J., Spence, M.A., Tager-Flusberg, H., Volkmar, F.R., Wrathall, D., 2004. Performance on Cambridge Neuropsychological Test Automated Battery subtests sensitive to

PESHAWAR JOURNAL OF PSYCHOLOGY AND BEHAVIORAL SCIENCES, 2018,VOL. 4, NO. 1, 139-152 
frontal lobe function in people with autistic disorder: evidence from the Collaborative Programs of Excellence in Autism network. Journal of Autism and Develop- mental Disorders 34, 139-150.

Raine, A. and Venables, P. (1992). Antisocial behaviour: Evolution, genetics, neuropsychology, and psychophysiology. In A. Gale and M. Eysenck (Eds.) Handbook of Individual Differences: Biological Perspectives. (287-321) John Wiley \& Sons Ltd. 1

Redick, T. S., Calvo, A., Gay, C. E., \& Engle, R. W. (2011). Working Memorycapacity and Go/No-Go Task Performance: Selective Effects of Updating, Maintenance, and Inhibition. Journal of Experimental Psychology: Learning, Memory, and Cognition, 37,308-324. https://doi.org/10.1037/a0022216

Schwartz, M., \& Johnson, J. H. (1985). Psychopathology of Childhood: A Clinical-Experimental Approach. $\left(2^{\text {nd }}\right.$ ed). Pergamon General Psychology Series, pg 309

Siegel, J. L. (2007). Criminology: Theories, Patterns, and Typologies.

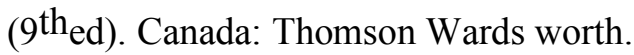

Smith, R. E., Persyn, D., \& Butler, P. (2011). Prospective memory, personality, and working memory: A formal modeling approach*. Zeitschriftfür Psychologie/Journal of Psychology, 219(2),108-116. http://dx.doi.org/10.1027/2151-2604/a000055

Stouthamer- Loeber, M., \&Loeber, R. (2002). Lost opportunities for intervention: undetected markers for the development of serious juvenile delinquency. Criminal Behaviour and Mental Health 12. 69-82.

Wolff, P.H., Waber, D., Bauermeister, M., Cohen, C., \& Ferber, R. (1982).The neuropsychological status of adolescent delinquent boys. Journal of Child Psychology and Psychiatry, 23(3), 267_279.

Yeudall, L. T, Fedora.O., \& Fromm, D. (1987). A neuropsychosocial theory of persistent criminality: Implications for assessment and treatment. Advances in Forensic Psychology and Psychiatry, 2,119-191. 